\title{
Epigallocatechin-3-gallate inhibits growth and induces apoptosis in esophageal cancer cells through the demethylation and reactivation of the p16 gene
}

\author{
JIANCHAO MENG ${ }^{1}$, QIANG TONG ${ }^{2},{\text { XIAOBO } \text { LIU }^{2}, \text { ZONGTAO YU }^{3}, \text { JICAI ZHANG }^{3} \text { and BO GAO }}^{3}$ \\ Departments of ${ }^{1}$ Oncology, ${ }^{2}$ Gastroenterology and ${ }^{3}$ Laboratory Medicine, Taihe Hospital, \\ Hubei University of Medicine, Shiyan, Hubei 442000, P.R. China
}

Received July 31, 2015; Accepted November 1, 2016

DOI: $10.3892 / \mathrm{ol} .2017 .6248$

\begin{abstract}
The present study aimed to investigate the effect of treatment with epigallocatechin-3-gallate (EGCG) on the human esophageal cancer cell line ECa109 and elucidate the associated underlying mechanisms. ECa109 cells were cultured and treated with increasing concentrations of EGCG for various durations. Cell viability was evaluated using the MTT assay and apoptosis was detected using flow cytometry. The methylation status of the cyclin-dependent kinase inhibitor 2A (p16) gene was analyzed using the methylation-specific polymerase chain reaction (PCR). p16 mRNA and protein expression was measured using reverse transcription-quantitative PCR and western blot analysis, respectively. The results of the present study demonstrated that, following treatment with EGCG, ECa109 cell viability was significantly decreased, while the rate of apoptosis was significantly increased $(\mathrm{P}<0.01)$, in a dose- and time-dependent manner. Following treatment of ECa109 cells with EGCG, p16 gene demethylation, and its mRNA and protein expression, were significantly increased compared with the untreated cells $(\mathrm{P}<0.01)$. EGCG may induce ECa109 cell apoptosis and inhibit cell growth through p16 gene demethylation, which restores its expression.
\end{abstract}

\section{Introduction}

Esophageal cancer is one of the most frequent malignant tumors of the digestive tract, and China has the highest incidence of esophageal cancer in the world (1). Currently, cisplatin-based adjuvant chemotherapy is an important method used in the treatment of esophageal cancer. However, this type of chemotherapy has multiple side effects, which certain

Correspondence to: Professor Qiang Tong, Department of Gastroenterology, Taihe Hospital, Hubei University of Medicine, 32 People South Road, Shiyan, Hubei 442000, P.R. China

E-mail: mcdoccn@163.com

Key words: esophageal cancer, epigallocatechin-3-gallate, cyclin-dependent kinase inhibitor 2A, methylation patients are unable to tolerate (2). Therefore, the development of low-toxicity and efficient chemotherapeutics for the treatment of esophageal cancer is required $(3,4)$.

Tea is a beverage made from the leaves of the Theaceae family of plants. The annual production and consumption of tea leaves worldwide surpasses $>3$ billion $\mathrm{kg}$. The consumption of green tea is popular in Asia, particularly in China. In recent years, a number of researchers have studied various green tea extracts (5). It has been demonstrated that green tea is able to inhibit the occurrence and development of the majority of human tumor types (6). Between 30 and $42 \%$ of dry green tea by weight is formed of catechins, which include (-)-epicatechin, (-)-epicatechin-3-gallate, (-)-epigallocatechin and (-)-epigallocatechin-3-gallate (EGCG) (7). EGCG has been observed to exhibit significant antitumor effects (8). It has been demonstrated that EGCG is able to affect a number of signaling pathways in the body (9-12); however, the underlying molecular mechanisms remain to be completely elucidated. In the present study, the effect of treatment with EGCG on the human esophageal cancer cell line ECa109 was investigated and the associated mechanisms were discussed. The aim of the present study was to provide a basis for the further application of EGCG in the treatment of human esophageal cancer.

\section{Materials and methods}

Cell culture. The esophageal carcinoma cell line ECa109 was obtained from the China Center for Type Culture Collection (Wuhan, China). Cells were cultured in Dulbecco's modified Eagle's medium containing 10\% fetal bovine serum (Gibco; Thermo Fisher Scientific, Inc., Waltham, MA, USA), 100 IU/ml penicillin and $100 \mu \mathrm{g} / \mathrm{ml}$ streptomycin at $37^{\circ} \mathrm{C}$ in an atmosphere containing $5 \% \mathrm{CO}_{2}$. EGCG (>98\% purity) was obtained from Sigma-Aldrich (Merck Millipore, Darmstadt, Germany), solubilized in PBS and stored at $-20^{\circ} \mathrm{C}$ until required.

Cell viability. ECa109 cells were inoculated into 96-well plates at a density of 5,000 cells/well and incubated at $37^{\circ} \mathrm{C}$ overnight. The cells were subsequently treated with $0,25,50$, 100 and $200 \mathrm{mg} / \mathrm{l} \mathrm{EGCG}$ and incubated for a further $96 \mathrm{~h}$. Cell viability was measured using the MTT $(5 \mathrm{mg} / \mathrm{ml})$ assay at $24,48,72$ and $96 \mathrm{~h}$. The assay was incubated at $37^{\circ} \mathrm{C}$ for 
$4 \mathrm{~h}$ and formazan crystals were dissolved by dimethyl sulfoxide, then the absorbance (optical density) was measured at the wavelength of $492 \mathrm{~nm}$. The percentages of viable cells were calculated using the following formula: Viable cells $(\%)=$ value of absorbance in experimental group/value of absorbance in control group x 100 (13).

Flow cytometry. A total of $1 \times 10^{6}$ ECa109 cells were inoculated into 6-well plates and treated with increasing concentrations of EGCG for $96 \mathrm{~h}$. Following treatment, the cells were trypsinized, washed with PBS and labeled with fluorescein isothiocyanate (FITC)-tagged Annexin V and propidium iodide (Annexin V-FITC Apoptosis Detection kit; KeyGen Biotech Co., Ltd., Nanjing, China), according to the manufacturer's protocol, and the data was analyzed and quantified by Windows Multiple Document Interafce for Flow Cytometry (WinMDI) version 2.9.

Methylation-specific polymerase chain reaction (MSP). Following treatment with increasing concentrations of EGCG for $96 \mathrm{~h}$, the cells were harvested and the cell density was $5 \times 10^{6}$, subsequent to washing with PBS and DNA was extracted using the DNeasy Tissue kit (Qiagen, Inc., Valencia, CA, USA), according to the manufacturer's protocol. The DNA was subsequently denatured using $0.2 \mathrm{M} \mathrm{NaOH}$, treated with $3.3 \mathrm{M}$ sodium bisulfite and $0.66 \mathrm{mM}$ hydroquinone, purified using the Wizard ${ }^{\circledR}$ DNA Clean-Up kit (Promega Corporation, Madison, WI, USA) and eluted with $\mathrm{H}_{2} \mathrm{O}$. The DNA was diluted using the $\mathrm{NaOH}$ to give a final concentration of $0.3 \mathrm{M}$, prior to desulfonation and purification, and the $\mathrm{pH}$ value was 5.0.

The following primers were used to perform the MSP (14): Cyclin-dependent kinase inhibitor 2A (p16) methylated DNA forward, 5'-TTATTAGAGGGTGGGGCGGATCGC-3' and reverse, 5'-GACCCCGAACCGCGACCGTAA-3' (final product, $150 \mathrm{bp}$ ); and p16 unmethylated DNA forward, 5'-TTATTAGAGGGTGGGGTGGATTGT-3' and reverse, 5'-CAACCCCAAACCACAACCATAA-3' (final product, $151 \mathrm{bp})$. The following thermocycling conditions were used: $95^{\circ} \mathrm{C}$ for $30 \mathrm{sec}$; 40 cycles of $95^{\circ} \mathrm{C}$ for $15 \mathrm{~min}, 56^{\circ} \mathrm{C}$ for $50 \mathrm{sec}$ and $72^{\circ} \mathrm{C}$ for $10 \mathrm{~min}$; and $72^{\circ} \mathrm{C}$ for $50 \mathrm{sec}$. All assays were performed in triplicate. The PCR products were analyzed using agarose gel $(25 \mathrm{mg} / \mathrm{ml})$ electrophoresis with the visualization agent of bromophenol blue, and the relative signal intensity was quantified using the G:BOX Gel Imaging and Analysis system F3 (Syngene, Cambridge, UK).

Reverse transcription-quantitative polymerase chain reaction $(R T-q P C R)$. Total RNA $(2 \mu \mathrm{l})$ was extracted from $\sim 5 \times 10^{6}$ ECa109 cells using TRIzol ${ }^{\circledR}$ reagent (Promega Corporation). RT-PCR was performed by Taq DNA polymerase (Invitrogen Platinum; Thermo Fisher Scientific, Inc.) using the AccessQuick $^{\mathrm{TM}}$ RT-PCR system (Sangon Biotech Co., Ltd., Shanghai, China), according to the manufacturer's protocol. The following primers were used: p16 forward, 5'-CCCAAC GCACCGAATAGTTAC-3' and reverse, 5'-ATTCCAATT CCCCTGCAAACT-3'; and GAPDH forward, 5'-GAAGGT GAAGGTCGGAGTC-3' and reverse, 5'-GAAGATGGTGAT GGGATTTC-3'. The conditions of reaction were as follows: 42 cycles of $95^{\circ} \mathrm{C}$ for $30 \mathrm{sec}, 55^{\circ} \mathrm{C}$ for $45 \mathrm{sec}$ and $72^{\circ} \mathrm{C}$ for $60 \mathrm{sec}$. Following 40 amplification, the $\mathrm{Cq}$ value was calculated using

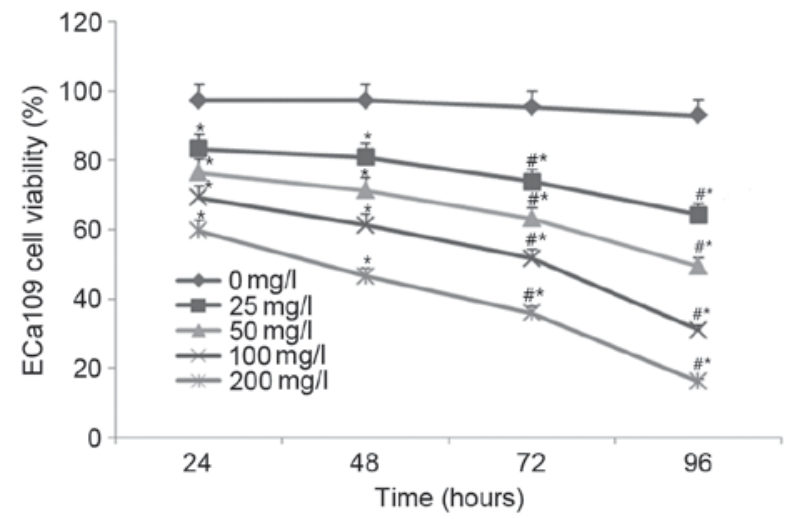

Figure 1. Treatment with epigallocatechin-3-gallate inhibits ECa109 cell viability. ${ }^{*} \mathrm{P}<0.05$ vs. the untreated cells at each time point; ${ }^{\sharp} \mathrm{P}<0.05$ vs. any 2 time points ( 24 vs. $48 ; 24$ vs. $72 ; 24$ vs. $96 ; 48$ vs. $72 ; 48$ vs. 96 ; and 72 vs. $96 \mathrm{~h})$ at the same concentration $(25,50,100$ and $200 \mathrm{mg} / \mathrm{l})$ groups.

the $2^{-\Delta \Delta \mathrm{Cq}}$ method (15) and the p16 mRNA expression relative to GAPDH was quantified using the following formulae: $\Delta \mathrm{Cq}_{\mathrm{p} 16}=\mathrm{Cq}_{\mathrm{p} 16}-\mathrm{CT}_{\mathrm{GAPDH}} ; \Delta \Delta \mathrm{Cq}=\Delta \mathrm{Cq}_{\mathrm{p} 16}-\Delta \mathrm{Cq}_{\mathrm{GAPDH}}$.

Western blotting. Following washing with ice-cold PBS, the cells $\left(1 \times 10^{7}\right)$ were lysed for $10 \mathrm{~min}$ in radioimmunoprecipitation assay buffer (Fuzhou Maixin Biotech Co., Ltd., Fuzhou, China). Total protein concentration was determined using the Coomassie Brilliant Blue assay. Total protein was separated using $10 \%$ SDS-PAGE, $30 \mu \mathrm{g}$ per lane, and subsequently transferred to a polyvinylidene difluoride membrane (Immobilon-P; Merck Millipore, Shanghai, China). The membrane was blocked with 5\% skimmed milk powder in TBS at room temperature for $1 \mathrm{~h}$ and subsequently incubated with rabbit anti-human p16 polyclonal antibody (cat. no. bs-1856R; 1:500; Beijing Biosynthesis Biotechnology Co., Ltd., Beijing, China) at $4^{\circ} \mathrm{C}$ overnight and washed with TBST 3 times prior to use. GAPDH was blotted as an internal reference using the anti-GAPDH rabbit polyclonal antibody (cat. no. AB21612-1; 1:5,000; AbSci, LLC, Portland, OR, USA). The membrane was washed with TBS containing Tween-20 three times and incubated with goat anti-rabbit IgG horseradish peroxidase-conjugated secondary antibody (cat. no. bs-0295G-HRP; 1:5,000; Beijing Biosynthesis Biotechnology Co., Ltd.) for at room temperature for 2 h. Following washing by TBST for 3 times, protein bands were visualized using the ECL Western Blotting Detection kit (Zhejiang Tianhang Biological Technology Co., Ltd, Hangzhou, China).

Statistical analysis. Values are presented as the mean \pm standard deviation. All statistical analysis was performed using SPSS software (version 17.0; SPSS Inc., Chicago, IL, USA). Multi-group comparisons of the means were carried out using one-way analysis of variance and the Student-Newman-Keuls post hoc test. $\mathrm{P}<0.05$ was considered to indicate a statistically significant difference.

\section{Results}

Treatment with EGCG inhibits ECa109 cell viability. As shown in Fig. 1, no significant difference in cell viability 

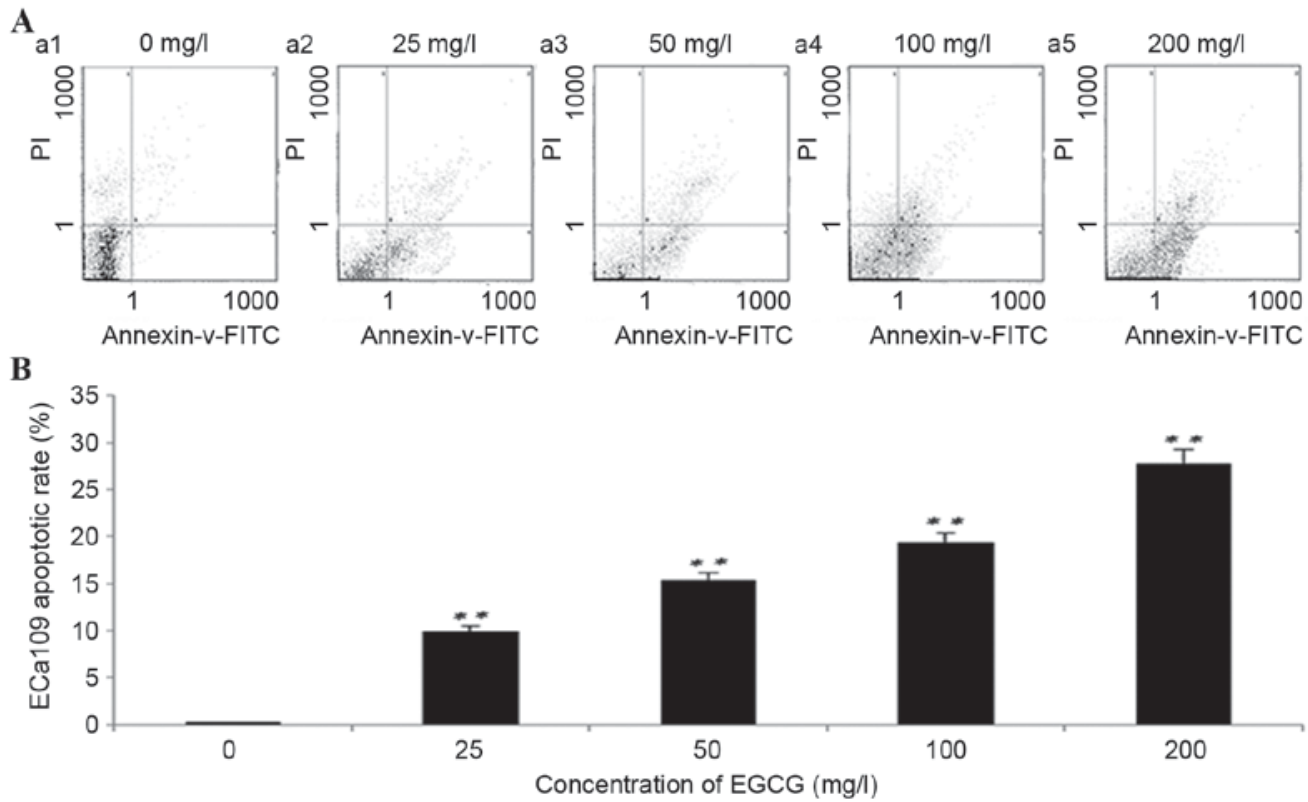

Figure 2. Treatment with EGCG increases the rate of apoptosis in ECa109 cells. (A) Flow cytometric analysis of ECa109 cell apoptosis. (B) Quantification of the rate of apoptosis in ECa109 cells. ${ }^{* *} \mathrm{P}<0.01$ vs. the untreated cells. EGCG, epigallocatechin-3-gallate; PI, propidium iodide; FITC, fluorescein isothiocyanate.

was observed for the untreated $(0 \mathrm{mg} / \mathrm{l})$ cells between the time points $(24,48,72$ and $96 \mathrm{~h})$. Following treatment with 25, 50, 100 and $200 \mathrm{mg} / \mathrm{l} \mathrm{EGCG}, \mathrm{ECa} 109$ cell viability was significantly decreased in a time- and concentration-dependent manner compared with the untreated cells at all time points (all $\mathrm{P}<0.05$; Fig. 1). These results indicate that treatment with EGCG significantly inhibits ECa109 cell viability.

Treatment with EGCG increases the rate of apoptosis in ECa109 cells. Following $96 \mathrm{~h}$ of treatment with EGCG, the rate of ECa109 apoptosis increased significantly at all concentrations compared with the untreated cells $(\mathrm{P}<0.01$; Fig. 2). ECa109 apoptosis rates following treatment with 25 , 50,100 and $200 \mathrm{mg} / 1 \mathrm{EGCG}$ were $9.98 \pm 0.32,15.60 \pm 1.54$, $19.40 \pm 2.89$ and $27.20 \pm 2.01 \%$, respectively. The differences between each group were $\mathrm{P}<0.001$, with the exception of $50 \mathrm{mg} / \mathrm{l}$ vs. $100 \mathrm{mg} / \mathrm{l}(\mathrm{P}=0.008)$. These results suggest that treatment with EGCG significantly induces ECa109 cell apoptosis.

Treatment with EGCG increases pl6 gene demethylation. The results of the MSP analysis indicated that the p16 gene was hypermethylated in ECa109 cells prior to treatment with EGCG (Fig. 3). Demethylated p16 DNA levels were markedly increased following treatment with 50,100 and $200 \mathrm{mg} / \mathrm{l}$ EGCG in a concentration-dependent manner (Fig. 3).

Treatment with EGCG increases p16 mRNA expression. As shown in Fig. 4A and B, treatment with EGCG induced the expression of the p16 gene at the mRNA level. p16 mRNA levels increased significantly following treatment with 50, 100 and $200 \mathrm{mg} / \mathrm{l}$ EGCG compared with the untreated cells $(\mathrm{P}<0.01$; Fig. 4B). The fold-changes in p16 expression levels following treatment with 25, 50, 100 and $200 \mathrm{mg} / \mathrm{l} \mathrm{EGCG}$ were $1.18 \pm 0.43,1.29 \pm 0.11,1.52 \pm 0.74$ and $1.67 \pm 0.37$, respectively, as compared with the untreated cells.

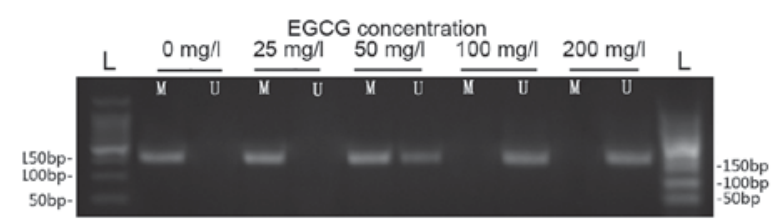

Figure 3. Treatment with EGCG increases cyclin-dependent kinase inhibitor 2A gene demethylation. L, DNA ladder; M, methylated fragment; U, unmethylated fragment; EGCG, epigallocatechin-3-gallate.

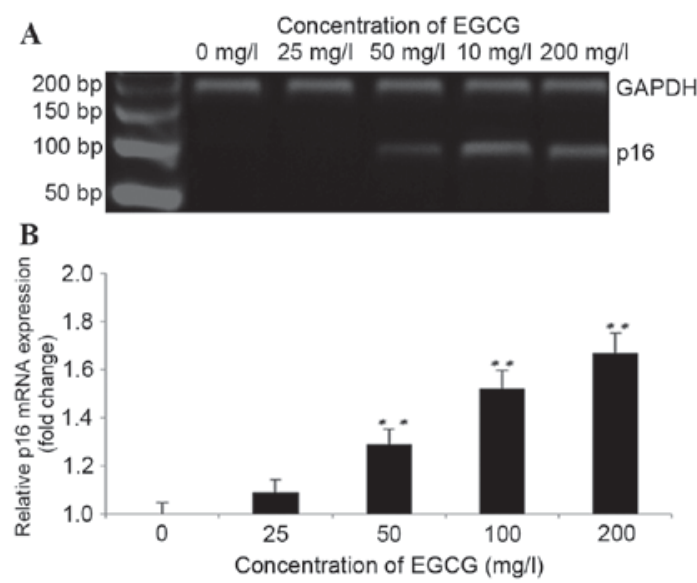

Figure 4. Treatment with EGCG leads to increased p16 mRNA expression. (A) Results of the agarose gel electrophoresis. (B) Quantitated p16 mRNA expression levels relative to GAPDH. ${ }^{* *} \mathrm{P}<0.01$ vs. the untreated cells. EGCG, epigallocatechin-3-gallate; p16, cyclin-dependent kinase inhibitor $2 \mathrm{~A}$.

Treatment with EGCG increases p16 protein expression. As shown in Fig. 5A and B, p16 protein expression was increased following treatment with EGCG in a concentration-dependent manner. P16 protein expression was markedly increased 


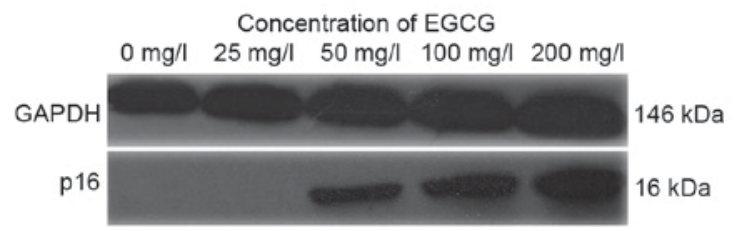

Figure 5. Treatment with EGCG increases p16 protein expression following the results of the western blot analysis. EGCG, epigallocatechin-3-gallate; p16, cyclin-dependent kinase inhibitor $2 \mathrm{~A}$

following treatment with 50, 100 and $200 \mathrm{mg} / \mathrm{ml} \mathrm{EGCG}$ compared with the untreated cells (Fig. 5).

\section{Discussion}

Epidemiological surveys $(16,17)$ and in vivo studies $(18-20)$ have confirmed that green tea and its extracts have antitumor effects, although the underlying molecular mechanisms remain unclear. A previous study observed that EGCG, the primary component of polyphenols in green tea, increased the methylation of the estrogen receptor- $\alpha(E R \alpha)$ gene, which promoted ER $\alpha$ protein expression and improved the sensitivity of ER $\alpha$-negative breast cancer cells to chemotherapeutic drugs (13). Furthermore, EGCG was able to induce the demethylation of the WNT inhibitory factor 1 and reversion-inducing cysteine-rich protein with kazal motifs genes, and restore their expression in pulmonary and oral squamous cell carcinoma, thus inhibiting the growth of tumor cells $(21,22)$.

An epigenetic study demonstrated that abnormal DNA methylation may lead to unstable gene expression, and is involved in the occurrence and development of tumors (23). The p16 protein, encoded for by the p16 gene, leads to $G_{1}$ phase cell cycle arrest, and thus inhibits cell proliferation and malignant transformation (24). Dysregulation of the p16 gene leads to unregulated cell proliferation and subsequent tumorigenesis. p16 protein inactivation has a high incidence in esophageal cancer and is caused by increased methylation of the p16 gene promoter region (21).

The results of the present study indicate that treatment with EGCG had a significant inhibitory effect on ECa109 cell viability, and significantly induced apoptosis in a concentration-dependent manner. In addition, EGCG induced marked demethylation of the p16 gene, and significantly increased p16 mRNA and protein expression. Therefore, EGCG may inhibit ECa109 cell viability and induce apoptosis through the reversal of p16 gene methylation, thus increasing its protein expression.

DNA methylation is a procedure mediated by DNA methyltransferase (DNMT). During this process, the methyl group of an S-adenosylmethionine molecule is transferred to the fifth carbon atom in cytosine. The methylation and demethylation of DNA are a series of reversible enzymatic reactions. An abnormal methylation status exists, to varying extents, in the majority of tumors, which makes it a candidate strategy in the prevention and treatment of tumors (25) Fang et al (26) reported that EGCG was able to inhibit the activity of DNMT in the esophageal cancer cell line KYSE510, and subsequently reverse the methylation status of O-6-methylguanine DNMT, retinoic acid receptor- $\beta$ and other tumor-associated genes. This led to increased protein expression and induced tumor cell apoptosis. Therefore, EGCG may be a competitive inhibitor of DNMT. However, it remains unclear whether the reversal of p16 gene methylation following treatment with EGCG is due to the inhibition of DNMT. In addition, it remains unclear whether this phenomenon occurs in other tumor cell lines and tumor-associated genes, and whether there are synergistic or antagonistic mechanisms for p16 gene demethylation and its induction of tumor cell apoptosis. Therefore, further investigations are warranted.

In conclusion, the present study determined that treatment with EGCG was able to induce apoptosis in esophageal cancer ECa109 cells and reverse the methylation status of the tumor suppressor gene, p16. Furthermore, the present study identified the antitumor effects of EGCG and provided a basis for further application of EGCG to the treatment of esophageal cancer.

\section{References}

1. Gao QY and Fang JY: Early esophageal cancer screening in China. Best Pract Res Clin Gastroenterol 29: 885-893, 2015.

2. Aichler M, Motschmann M, Jütting U, Luber B, Becker K, Ott K, Lordick F, Langer R, Feith M, Siewert JR and Walch A: Epidermal growth factor receptor (EGFR) is an independent adverse prognostic factor in esophageal adenocarcinoma patients treated with cisplatin-based neoadjuvant chemotherapy. Oncotarget 5: 6620-6632, 2014.

3. Podolski-Renić A, Andelković T, Banković J, Tanić N, Ruždijić S and Pešić M: The role of paclitaxel in the development and treatment of multidrug resistant cancer cell lines. Biomed Pharmacother 65: 345-353, 2011.

4. Ding XW, Wu JH and Jiang CP: ABCG2: A potential marker of stem cells and novel target in stem cell and cancer therapy. Life Sci 86: 631-637, 2010.

5. He X, Gao B, Zhou L and Xiong S: Green tea polyphenol epigallocatechin-3-gallate alleviated coxsackievirus B3-induced myocarditis through inhibiting viral replication, but not through inhibiting inflammatory responses. J Cardiovasc Pharmacol 69: 41-47, 2017.

6. Yang CS and Landau JM: Effects of tea consumption on nutrition and health. J Nutr 130: 2409-2412, 2000.

7. Suganuma M, Takahashi A, Watanabe T, Iida K, Matsuzaki T, Yoshikawa HY and Fujiki H: Biophysical approach to mechanisms of cancer prevention and treatment with green tea catechins. Molecules 21: pii: E1566, 2016.

8. Balentine DA, Wiseman SA and Bouwens LC: The chemistry of tea flavonoids. Crit Rev Food Sci Nutr 37: 693-704, 1997.

9. Kerksick CM, Roberts MD, Dalbo VJ, Kreider RB and Willoughby DS: Changes in skeletal muscle proteolytic gene expression after prophylactic supplementation of EGCG and NAC and eccentric damage. Food Chem Toxicol 61: 47-52, 2013.

10. Shimizu M, Adachi S, Masuda M, Kozawa O and Moriwaki H: Cancer chemoprevention with green tea catechins by targeting receptor tyrosine kinases. Mol Nutr Food Res 55: 832-843, 2011.

11. Manohar M, Fatima I, Saxena R, Chandra V, Sankhwar PL and Dwivedi A: (-)-Epigallocatechin-3-gallate induces apoptosis in human endometrial adenocarcinoma cells via ROS generation and p38 MAP kinase activation. J Nutr Biochem 24: 940-947, 2013.

12. Kuhn DJ, Burns AC, Kazi A and Dou QP: Direct inhibition of the ubiquitin-proteasome pathway by ester bond-containing green tea polyphenols is associated with increased expression of sterol regulatory element-binding protein 2 and LDL receptor. Biochim Biophys Acta 1682: 1-10, 2004.

13. Li Y, Yuan YY, Meeran SM and Tollefsbol TO: Synergistic epigenetic reactivation of estrogen receptor- $\alpha(E R \alpha)$ by combined green tea polyphenol and histone deacetylase inhibitor in ER $\alpha$-negative breast cancer cells. Mol Cancer 9: 274, 2010.

14. Mir MR, Shabir N, Wani KA, Shaff S, Hussain I, Banday MA, Chikan NA, Bilal S and Aejaz S: Association between p16, hMLH1 and E-cadherin promoter hypermethylation and intake of local hot salted tea and sun-dried foods in Kashmiris with gastric tumors. Asian Pac J Cancer Prev 13: 181-186, 2012.

15. Livak KJ and Schmittgen TD: Analysis of relative gene expression data using real-time quantitative PCR and the 2(-Delta Delta C(T)) Method. Methods 25: 402-408, 2001. 
16. Wang Q, Wang Y, Ji Z, Chen X, Pan Y, Gao G, Gu H, Yang Y, Choi BC and Yan Y: Risk factors for multiple myeloma: A hospital-based case-control study in Northwest China. Cancer Epidemiol 36: 439-444, 2012.

17. Wang J, Zhang W, Sun L, Yu H, Ni QX, Risch HA and Gao YT: Green tea drinking and risk of pancreatic cancer: A large-scale, population-based case-control study in urban Shanghai. Cancer Epidemiol 36: e354-e358, 2012.

18. Wu H, Xin Y, Xiao Y and Zhao J: Low-dose docetaxel combined with (-)-epigallocatechin-3-gallate inhibits angiogenesis and tumor growth in nude mice with gastric cancer xenografts. Cancer Biother Radiopharm 27: 204-209, 2012.

19. Stearns ME, Amatangelo MD, Varma D, Varma D, Sell C and Goodyear SM: Combination therapy with epigallocatechin-3-gallate and doxorubicin in human prostate tumor modeling studies: Inhibition of metastatic tumor growth in severe combined immunodeficiency mice. Am J Pathol 177: 3169-3179, 2010.

20. Shankar S, Marsh L and Srivastava RK: EGCG inhibits growth of human pancreatic tumors orthotopically implanted in Balb C nude mice through modulation of FKHRL1/FOXO3a and neuropilin. Mol Cell Biochem 372: 83-94, 2013.

21. Kato K, Long NK, Makita H, Toida M, Yamashita T, Hatakeyama D, Hara A, Mori H and Shibata T: Effects of green tea polyphenol on methylation status of RECK gene and cancer cell invasion in oral squamous cell carcinoma cells. Br J Cancer 99: 647-654, 2008.
22. Gao Z, Xu Z, Hung MS, Lin YC, Wang T, Gong M, Zhi X, Jablon DM and You L: Promoter demethylation of WIF-1 by epigallocatechin-3-gallate in lung cancer cells. Anticancer Res 29: 2025-2030, 2009.

23. Lima SC, Hernández-Vargas H, Simão T, Durand G, Kruel CD, Le Calvez-Kelm F, Ribeiro Pinto LF and Herceg Z: Identification of a DNA methylome signature of esophageal squamous cell carcinoma and potential epigenetic biomarkers. Epigenetics 6: 1217-1227, 2011

24. Rocco JW and Sidransky D: p16 (MTS-1/CDKN2/INK4a) in cancer progression. Exp Cell Res 264: 42-55, 2001

25. Nazmul Islam M, Yadav S, Hakimul Haque M, Munaz A, Islam F, Al Hossain MS, Gopalan V, Lam AK, Nguyen NT and Shiddiky MJ: Optical biosensing strategies for DNA methylation analysis. Biosens Bioelectron 92: 668-678, 2017.

26. Fang M, Chen D and Yang CS: Dietary polyphenols may affect DNA methylation. J Nutr 137 (1 Suppl): 223S-228S, 2007. 